\title{
Synthesis, characterization and luminescence studies of gold(I)-NHC amide complexes
}

\author{
Adrián Gómez-Suárez ${ }^{1}$, David J. Nelson ${ }^{1}$, David G. Thompson², \\ David B. Cordes ${ }^{1}$, Duncan Graham ${ }^{2}$, Alexandra M. Z. Slawin ${ }^{1}$ \\ and Steven P. Nolan ${ }^{* 1}$
}

\section{Full Research Paper}

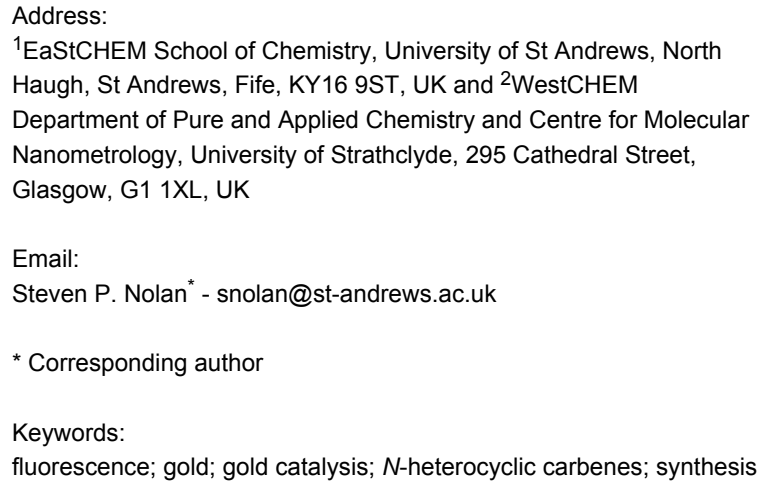

${ }^{1}$ EaStCHEM School of Chemistry, University of St Andrews, North Haugh, St Andrews, Fife, KY16 9ST, UK and ${ }^{2}$ WestCHEM Department of Pure and Applied Chemistry and Centre for Molecular Nanometrology, University of Strathclyde, 295 Cathedral Street, Glasgow, G1 1XL, UK

Email:

Steven P. Nolan * snolan@st-andrews.ac.uk

* Corresponding author

Keywords:

fluorescence; gold; gold catalysis; $N$-heterocyclic carbenes; synthesis

Open Access

\author{
Beilstein J. Org. Chem. 2013, 9, 2216-2223. \\ doi:10.3762/bjoc. 9.260 \\ Received: 15 July 2013 \\ Accepted: 10 October 2013 \\ Published: 28 October 2013 \\ This article is part of the Thematic Series "Gold catalysis for organic \\ synthesis II". \\ Guest Editor: F. D. Toste \\ (C) 2013 Gómez-Suárez et al; licensee Beilstein-Institut. \\ License and terms: see end of document.
}

\begin{abstract}
A flexible, efficient and straightforward methodology for the synthesis of $N$-heterocyclic carbene gold(I)-amide complexes is reported. Reaction of the versatile building block $[\mathrm{Au}(\mathrm{OH})(\mathrm{IPr})](\mathbf{1})(\mathrm{IPr}=1,3$-bis(2,6-diisopropylphenyl)imidazol-2-ylidene) with a series of commercially available (hetero)aromatic amines leads to the synthesis of several [Au(NRR')(IPr)] complexes in good yields and with water as the sole byproduct. Interestingly, these complexes present luminescence properties. UV-vis and fluorescence measurements have allowed the identification of their excitation and emission wavelengths $\left(\lambda_{\max }\right)$. These studies revealed that by selecting the appropriate amine ligand the emission can be easily tuned to achieve a variety of colors, from violet to green.
\end{abstract}

\section{Introduction}

The synthesis of organogold complexes has recently attracted wide attention due to their considerable range of applications, in areas such as materials and medicinal chemistry, as well as their potential role as reaction intermediates or new catalysts in goldcatalyzed processes [1-7]. This has led several research groups to investigate general, green and straightforward methodologies for the synthesis of organogold complexes. We have focused on the synthesis and study of transition metal complexes bearing $N$-heterocyclic carbene (NHC) ligands [8-10]. Recently, we have been very active in the synthesis and characterization of new gold(I)-NHC complexes and the study of their reactivity, with a special focus on the development of straightforward methodologies $[11,12]$. As a result of our investigations, we have recently reported the synthesis of $[\mathrm{AuX}(\mathrm{NHC})](\mathrm{X}=\mathrm{Cl}$, $\mathrm{Br}, \mathrm{I})$ complexes, directly from imidazolium and imidazolidinium salts and a suitable gold source, such as $\left[\mathrm{AuCl}\left(\mathrm{SMe}_{2}\right)\right]$, using $\mathrm{K}_{2} \mathrm{CO}_{3}$ as a base [13]. Moreover, we have also reported the synthesis of the first mononuclear gold(I) hydroxide species, 
[Au(OH)(IPr)] (1) (IPr = 1,3-bis(2,6-diisopropylphenyl)imidazol-2-ylidene), using [AuCl(IPr)] and an excess of $\mathrm{KOH}$ in THF $[14,15]$. This complex has proven to be an excellent synthon for the preparation of a wide variety of organogold(I) species [1623]. Two approaches have been developed for the synthesis of such species using hydroxide 1: a) via transmetallation from either boronic acids or siloxides, or b) via deprotonation reactions of suitable substrates. We have applied the latter methodology to the synthesis of organogold-NHC complexes bearing several trans-ligands, such as acetylene, phenyl and phenol derivatives. These reactions can be carried out using reagentgrade materials, without the requirement to exclude light, air or moisture; providing an easy, straightforward 3-step route for the synthesis of organogold-NHC complexes from readily available gold sources, such as $\left[\mathrm{Au}\left(\mathrm{SMe}_{2}\right) \mathrm{Cl}\right]($ Scheme 1).

Toste and Bergman have recently reported the synthesis, characterization and reactivity studies of a series of [Au(NRR')(NHC)] complexes [24]. This study represents the first reported synthesis of gold(I)-NHC amide complexes. The procedure employed for the synthesis of these species required the use of lithium amide reagents that are not stable towards air or moisture [24]. Therefore, the development of a more robust approach would be desirable. In addition to the interesting reactivity shown by Toste and Bergman, Hoffman and Viseux have probed the anticancer properties of gold amide complexes, reacting modified triflamide compounds with phosphinebearing gold chloride species [25]. Taking into account the interest in these type of complexes, we sought to use hydroxide 1 to develop an easy, green (in such deprotonation reactions, water is the sole byproduct) and straightforward methodology for the synthesis of gold(I)-amide complexes.

\section{Results and Discussion Synthesis and characterization of gold(I)-amide complexes}

We began our studies by exposing hydroxide 1 to a series of alkyl- and arylamines. While no reaction was observed with either morpholine or isopropylamine, the use of 1 equiv of aniline or 2-aminopyridine led to the isolation of complexes 2 and 3 respectively, in good yields after overnight reaction at room temperature. These results are consistent with the known $\mathrm{p} K_{\mathrm{a}}$ of $[\mathrm{Au}(\mathrm{OH})(\mathrm{IPr})]$ (30.3) [26]; the scope of this preparative route is, as with other deprotonation reactions with this building block, limited to substrates with a $\mathrm{p} K_{\mathrm{a}}$ lower than 30 .

Encouraged by these exploratory reactions, a series of (hetero)aromatic amines were employed to prepare the corresponding gold(I)-amide complexes. The desired complexes were obtained by reaction of $[\mathrm{Au}(\mathrm{OH})(\mathrm{IPr})]$ (1) with each (hetero)aromatic amine in THF at room temperature for $20 \mathrm{~h}$. A range of aromatic amines were employed, including aniline, diphenylamine, pyridines, a pyrimidine and one isoquinoline. The corresponding complexes were obtained in analytically pure form and in good yields as yellow or white microcrystalline powders after a simple work-up (Scheme 2). All complexes were characterized by ${ }^{1} \mathrm{H}$ and ${ }^{13} \mathrm{C}\left\{{ }^{1} \mathrm{H}\right\}$ NMR spectroscopy and elemental analysis (see Supporting Information File 1). The new species are bench stable in the solid state, and do not require special handling. However, some do decompose slowly in solution over the course of a number of hours.

A selected number of these complexes were characterized by $\mathrm{X}$-ray crystallography, as further support to confirm atom connectivity and molecular geometry (Figure 1) [27].

All complexes were found to display the expected twocoordinate linear geometry around the metal center, with all $\mathrm{C}-\mathrm{Au}-\mathrm{N}$ angles in the range $173-179^{\circ}$. There was no evidence of any interactions between the gold center and the heteroatoms in complexes 3, 7, 8, 10 or 11 . However, for 3, 7, 8, 10 and 11 there is an intermolecular contact between the aromatic nitrogen atom and the NHC ligand backbone proton $\left(\mathrm{d}_{\mathrm{N}-\mathrm{H}}=\right.$ $2.27 \AA-2.34 \AA$ ). All gold-carbon bond lengths were in the range $1.95 \AA$ (8) to $2.02 \AA$ (2), while gold-nitrogen bond lengths varied from $1.98 \AA$ (8) to $2.06 \AA$ (2).

During the characterization of the gold-NHC amide complexes we observed that some of the complexes possessed luminescent

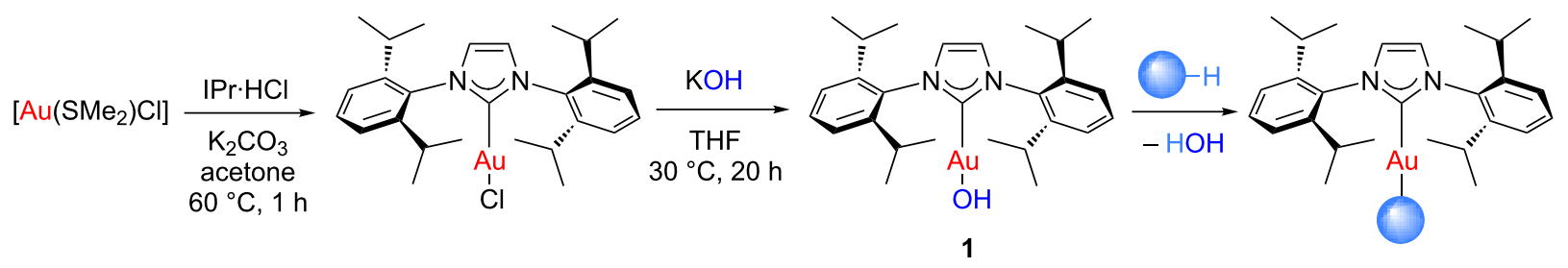



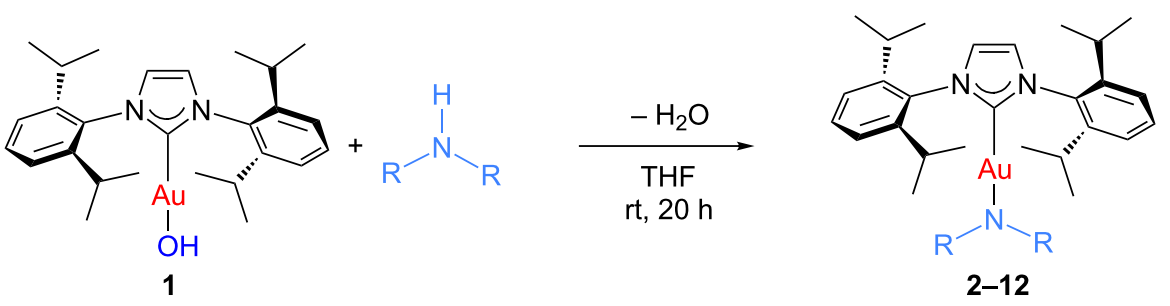

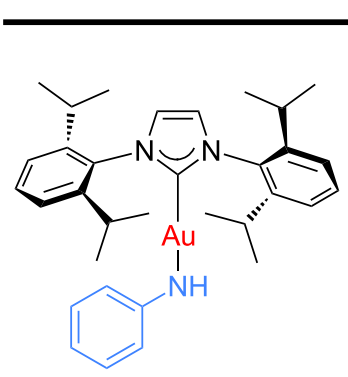

$266 \%$

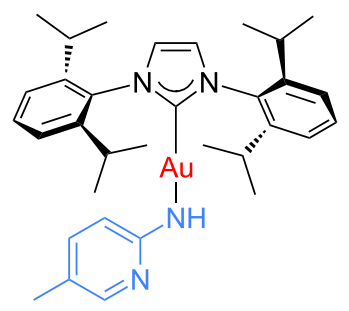

$681 \%$

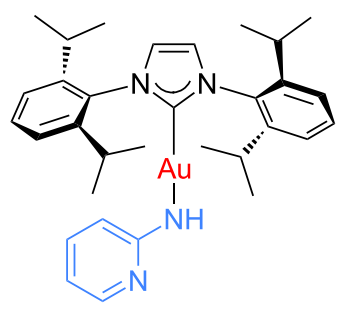

3 94\%

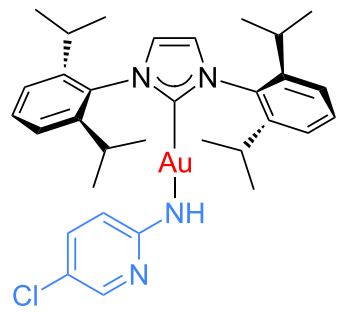

$787 \%$

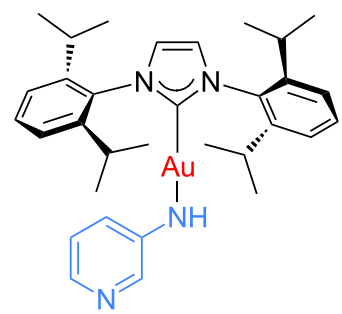

$485 \%$<smiles></smiles>

$872 \%$<smiles></smiles>

$588 \%$<smiles></smiles>

$983 \%$

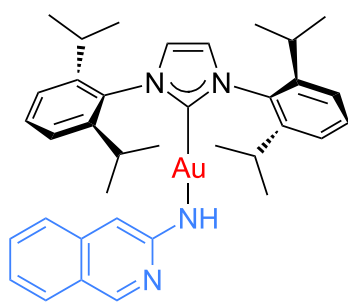

$1082 \%$

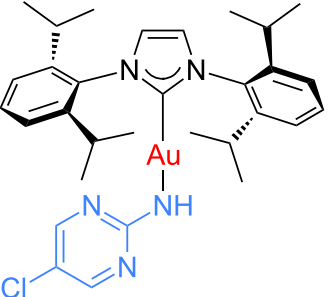

$1187 \%$

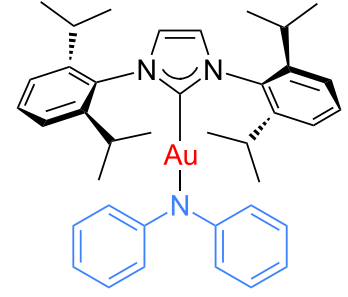

$1274 \%$

Scheme 2: Scope of the reaction between 1 and several (hetero)aromatic amines. Reaction conditions: 1 ( 1 equiv), amine (1 equiv), THF (0.5-2 mL), $\mathrm{rt}, 20 \mathrm{~h}$.

properties when exposed to ultraviolet light $(\lambda=366 \mathrm{~nm})$ in the solid state (Figure 2).

A number of luminescent organogold complexes have been reported in the literature, often demonstrating interesting properties that may lead to their application in materials science and the preparation of optical materials [28-34]. Amongst these, NHC-bearing gold complexes have been shown by several research groups to be very useful luminescent materials $[19,35$ 39], and have attracted industrial interest [40-42]. Thus, we decided to explore the potential of these gold amide species as luminescent materials.

We began our luminescence studies by recording the UV-vis spectra of the aforementioned gold-amide complexes using a dilute (ca. $0.2 \mathrm{mmol} / \mathrm{L}$ ) $\mathrm{CH}_{2} \mathrm{Cl}_{2}$ solution. The wavelengths of the absorption maxima on the $\mathrm{UV}$-vis spectra were in the range of 250-350 nm for most complexes, with the exception of 2-amino-5-nitropyridine derived 9 and 3-aminoisoquinolinederived 10, which exhibited absorption maxima at ca. $430 \mathrm{~nm}$ 

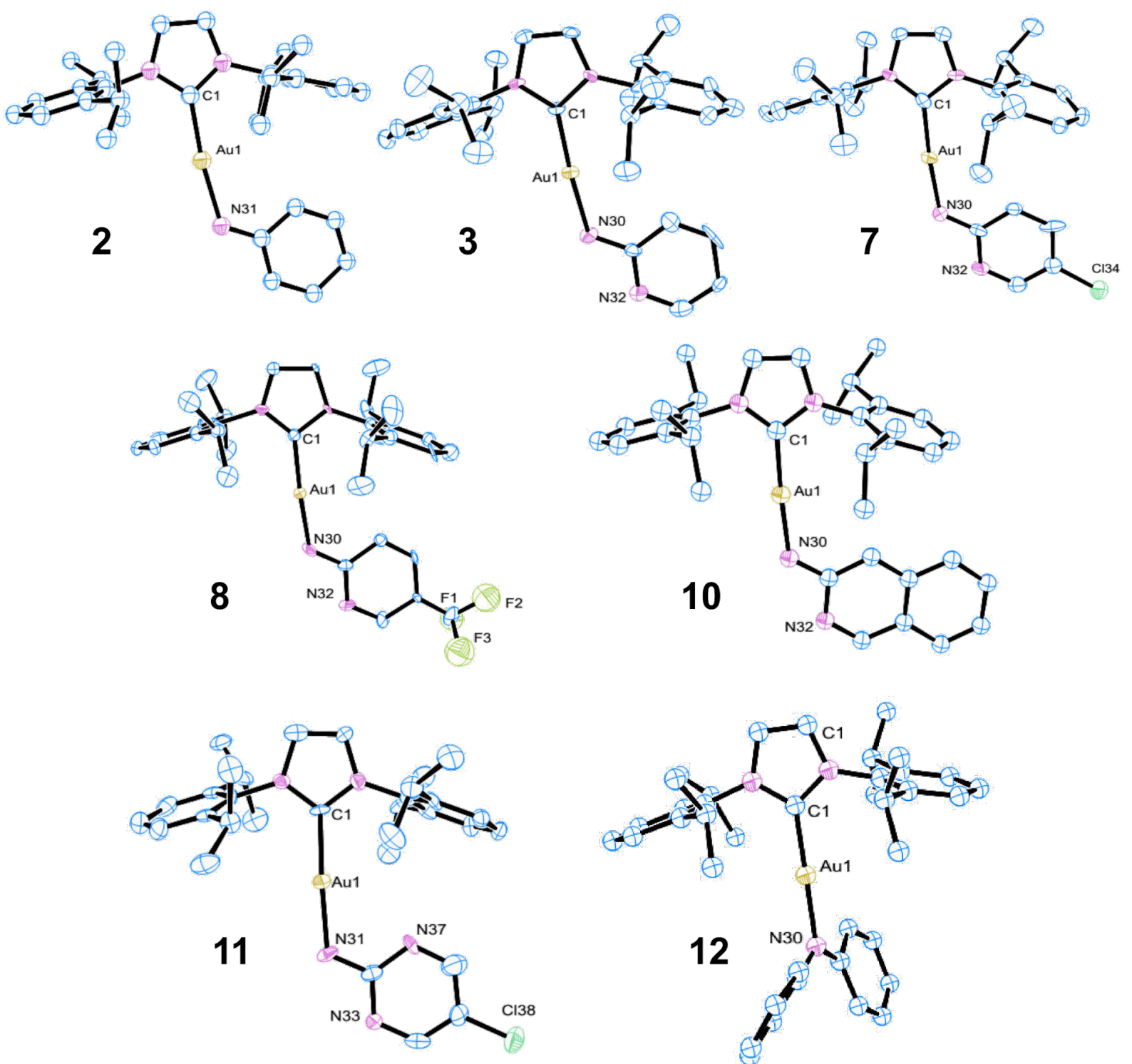

12
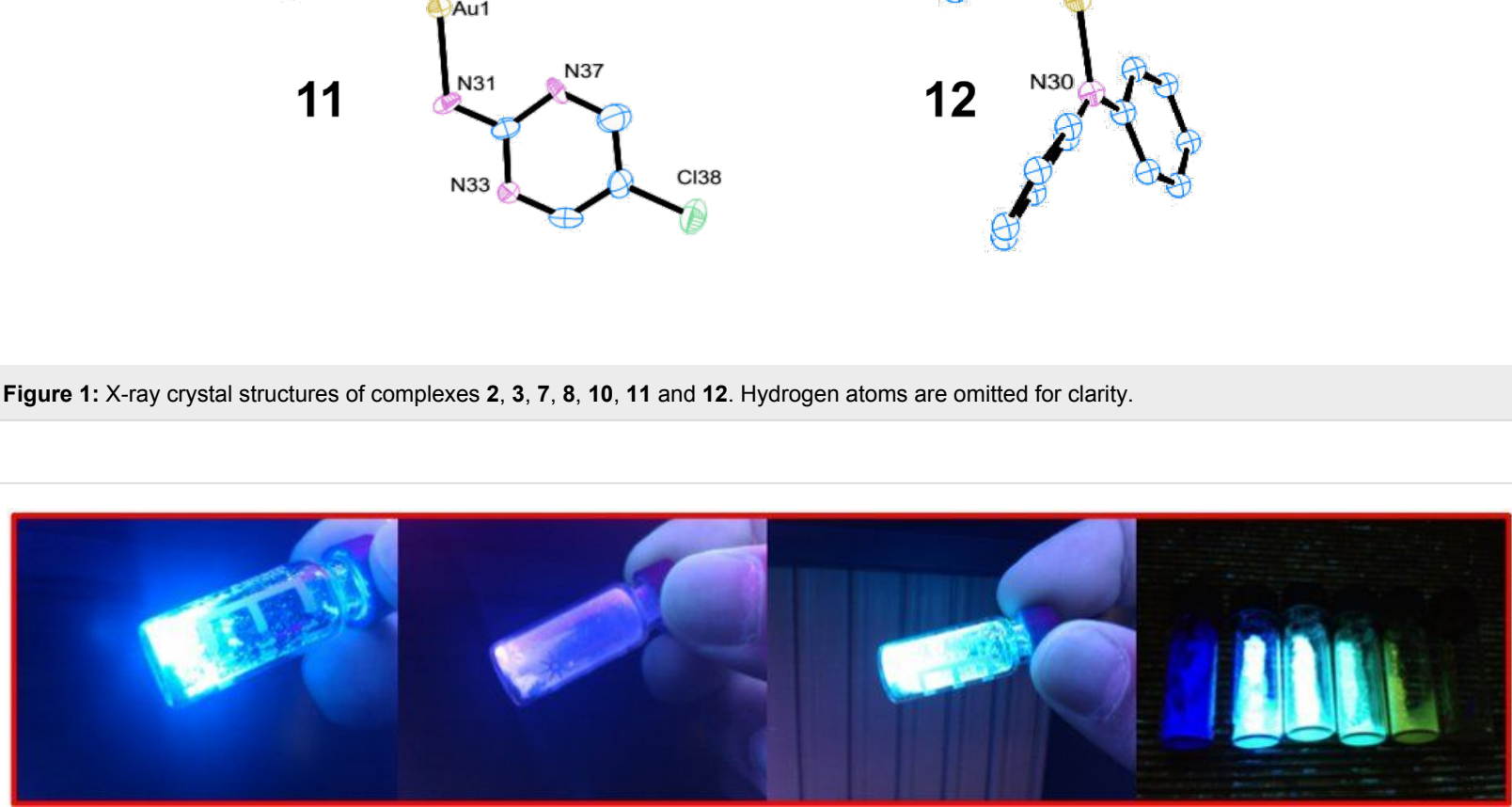

Figure 2: Selected examples of gold-NHC amide complexes under UV light $(\lambda=366 \mathrm{~nm})$. 
(see Supporting Information File 1). These data are consistent with the physical appearance of complexes 2-12 in the solution state, i.e. complexes $\mathbf{9}$ and $\mathbf{1 0}$ are yellow.

The excitation and emission maxima were then determined. These measurements were conducted on more concentrated (ca. $4 \mathrm{mmol} / \mathrm{L}$ ) $\mathrm{CH}_{2} \mathrm{Cl}_{2}$ solutions, compared to those used for UV-vis spectroscopy. In each case, the relevant maxima could be identified. An example dataset is presented in Figure 3. Lifetimes for all luminescence measurements were $\leq 1 \mu$ s (at the limit of the apparatus), suggesting that the luminescence was due to fluorescence, rather than phosphorescence.

The wavelengths of emission maxima spans the range 390 to $516 \mathrm{~nm}$, demonstrating that by selecting the appropriate amine ligand the emission can be easily tuned to achieve a variety of colors, i.e. from violet $\left(3, \lambda_{\max }=409 \mathrm{~nm}\right)$ to green $(4$ $\left.\lambda_{\max }=516 \mathrm{~nm}\right)$. In each case, there is a considerable Stokes shift (27 to $166 \mathrm{~nm}$ ). In terms of the intensity of emission, a wide range of values were recorded, although complexes could be considered as part of one of three distinct groups. Phenylbearing complexes (such as $\mathbf{2}$ and 12), 4-aminopyridine-derived 5 and electron-poor 9 showed relatively weak emission ( $<10$ AU). Electron-poor 2-aminopyridine derivatives, 3-aminopyridine-derived 4 and 2-amino-5-chloropyrimidinederived 11 exhibited moderate emission intensity (ca. 10-50 AU). The most intense fluorescence was observed with complexes 3, 6 and 10: 2-pyridine derivatives without electronwithdrawing substituents (ca. 120-290 AU) (Table 1).

DFT calculations were used to probe the nature of the frontier orbitals of complex 3 (at the M06-L/SDD level of theory) [43] using Gaussian 09 [44]. The LUMO, HOMO and HOMO-1 are pictured in Figure 4. While the HOMO and HOMO-1 are

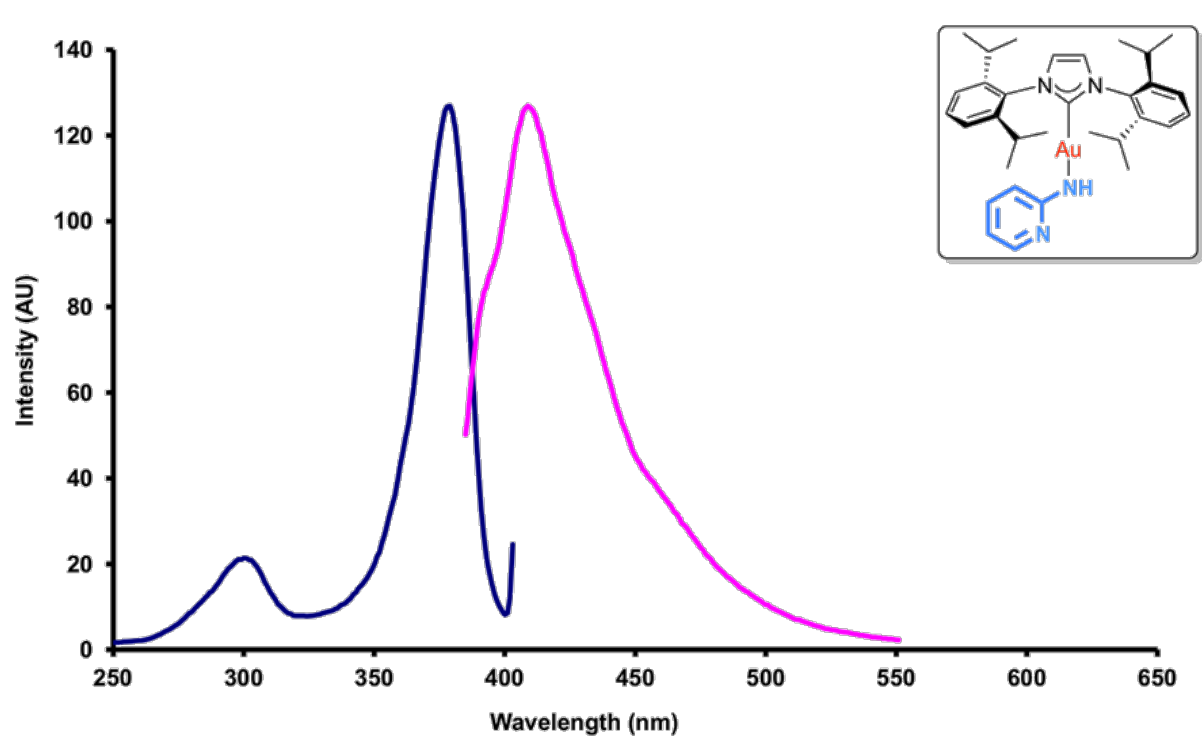

Figure 3: Excitation (blue) and emission (pink) data for complex 3, bearing a 2-pyridine ligand (see inset).
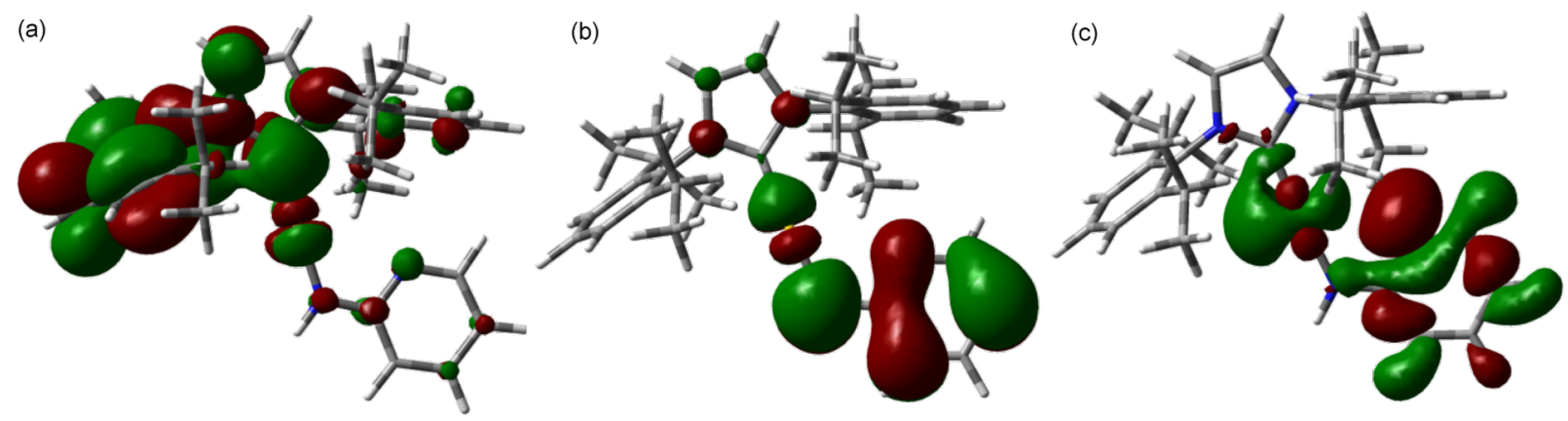

Figure 4: (a) LUMO, (b) HOMO and (c) HOMO-1 of complex 3. 
Table 1: Fluorescence measurement data. ${ }^{a}$

\begin{tabular}{|c|c|c|c|c|}
\hline entry & substituent & $\lambda_{\max } /$ excitation $(\mathrm{nm})$ & $\lambda_{\max } /$ emission $(\mathrm{nm})$ & intensity $\max _{(A U)}$ \\
\hline 1 & 2 & 396 & 423 & 3.8 \\
\hline 2 & 12 & 410 & 470 & 4.61 \\
\hline 3 & 5 & 352 & 390 & 7.25 \\
\hline 4 & & 350 & 516 & 1.09 \\
\hline 5 & 4 & 398 & 454 & 21.2 \\
\hline 6 & 8 & 368 & 406 & 12.8 \\
\hline 7 & 7 & 395 & 428 & 45.8 \\
\hline 8 & 11 & 385 & 435 & 36.0 \\
\hline 9 & 3 & 379 & 409 & 126 \\
\hline 10 & 6 & 389 & 420 & 119 \\
\hline 11 & 10 & 471 & 505 & 293 \\
\hline
\end{tabular}

aAt ca. $4 \mathrm{mmol} / \mathrm{L}$ in $\mathrm{CH}_{2} \mathrm{Cl}_{2}$ solution.

centered predominantly on the amide ligand, the LUMO is localized on the aryl ring of the NHC ligand; we propose that the fluorescence behavior is due to a HOMO-to-LUMO transition. Therefore, the use of different NHC ligands should also allow access to different fluorescence behavior.

\section{Conclusion}

A novel series of NHC-bearing gold(I)-amide complexes have been prepared using a simple, straightforward synthetic route that can be conducted using reagent-grade materials on the laboratory bench in air. The resulting species have been charac- 
terized using a number of methods, including NMR spectroscopy and X-ray crystal diffraction. These new species have been shown to be fluorescent, and their absorbance and emission maxima have been determined. Notably, there are key trends in the fluorescence behavior of these materials, with more electron-rich 2-pyridine derivatives showing strong emission, and isoquinoline-derived complexes showing the strongest fluorescence. While the present study has been conducted using commercial reagent-grade amines, there is significant scope to prepare a much wider range of gold(I)-amide complexes, including those prepared using designed aromatic amines. Further work is underway in our group to explore both the potential of gold(I)-NHC amide complexes, and further applications of gold(I) hydroxides as building blocks and catalysts.

\section{Supporting Information}

\section{Supporting Information File 1}

Experimental part.

[http://www.beilstein-journals.org/bjoc/content/

supplementary/1860-5397-9-260-S1.pdf]

\section{Acknowledgements}

SPN thanks the ERC (Advanced Investigator AwardFUNCAT), EPSRC and Syngenta for support, and Umicore AG for their generous gift of materials. D.G. and S.P.N. are Royal Society Wolfson Merit Award holders. We thank EaStCHEM for computational support through the EaStCHEM Research Computing Facility.

\section{References}

1. Marcon, G.; Messori, L.; Orioli, P. Expert Rev. Anticancer Ther. 2002, 2, 337-346. doi:10.1586/14737140.2.3.337

2. Hashmi, A. S. K.; Hutchings, G. J. Angew. Chem., Int. Ed. 2006, 45 , 7896-7936. doi:10.1002/anie.200602454

3. Hashmi, A. S. K. Gold Bull. 2009, 42, 275-279. doi:10.1007/BF03214949

4. He, X.; Yam, V. W.-W. Coord. Chem. Rev. 2011, 255, 2111-2123. doi:10.1016/j.ccr.2011.02.003

5. Liu, L.-P.; Hammond, G. B. Chem. Soc. Rev. 2012, 41, 3129-3139. doi:10.1039/c2cs15318a

6. Schmidbaur, H.; Schier, A. Chem. Soc. Rev. 2012, 41, 370-412. doi:10.1039/c1cs15182g

7. Gómez-Suárez, A.; Nolan, S. P. Angew. Chem., Int. Ed. 2012, 51, 8156-8159. doi:10.1002/anie.201203587

8. Díez-González, S.; Marion, N.; Nolan, S. P. Chem. Rev. 2009, 109, 3612-3676. doi:10.1021/cr900074m

9. Nelson, D. J.; Nolan, S. P. Chem. Soc. Rev. 2013, 42, 6723-6753. doi:10.1039/c3cs60146c

10. de Frémont, P.; Marion, N.; Nolan, S. P. Coord. Chem. Rev. 2009, 253, 862-892. doi:10.1016/j.ccr.2008.05.018

11. Marion, N.; Nolan, S. P. Chem. Soc. Rev. 2008, 37, 1776-1782. doi:10.1039/b711132k
12. Nolan, S. P. Acc. Chem. Res. 2011, 44, 91-100. doi:10.1021/ar1000764

13. Collado, A.; Gómez-Suárez, A.; Martin, A. R.; Slawin, A. M. Z.; Nolan, S. P. Chem. Commun. 2013, 49, 5541-5543. doi:10.1039/c3cc43076f

14. Gaillard, S.; Slawin, A. M. Z.; Nolan, S. P. Chem. Commun. 2010, 46, 2742-2744. doi:10.1039/c0cc00018c

15. Gómez-Suárez, A.; Ramón, R. S.; Slawin, A. M. Z.; Nolan, S. P. Dalton Trans. 2012, 41, 5461-5463. doi:10.1039/c2dt30294b

16. Dupuy, S.; Slawin, A. M. Z.; Nolan, S. P. Chem.-Eur. J. 2012, 18, 14923-14928. doi:10.1002/chem.201202299

17. Dupuy, S.; Crawford, L.; Bühl, M.; Slawin, A. M. Z.; Nolan, S. P. Adv. Synth. Catal. 2012, 354, 2380-2386. doi:10.1002/adsc.201200233

18. Dupuy, S.; Lazreg, F.; Slawin, A. M. Z.; Cazin, C. S. J.; Nolan, S. P. Chem. Commun. 2011, 47, 5455-5457. doi:10.1039/c1cc10917k

19. Fortman, G. C.; Poater, A.; Levell, J. W.; Gaillard, S.; Slawin, A. M. Z.; Samuel, I. D. W.; Cavallo, L.; Nolan, S. P. Dalton Trans. 2010, 39, 10382-10390. doi:10.1039/c0dt00276c

20. Gaillard, S.; Rix, D.; Slawin, A. M. Z.; Lacour, J.; Nolan, S. P. Dalton Trans. 2012, 41, 8235-8237. doi:10.1039/c2dt30440f

21. Konkolewicz, D.; Gaillard, S.; West, A. G.; Cheng, Y. Y.; Gray-Weale, A.; Schmidt, T. W.; Nolan, S. P.; Perrier, S. Organometallics 2011, 30, 1315-1318. doi:10.1021/om200103f

22. Gaillard, S.; Nun, P.; Slawin, A. M. Z.; Nolan, S. P. Organometallics 2010, 29, 5402-5408. doi:10.1021/om100456b

23. Egbert, J. D.; Slawin, A. M. Z.; Nolan, S. P. Organometallics 2013, 32, 2271-2274. doi:10.1021/om301187a

24. Johnson, M. W.; Shevick, S. L.; Toste, F. D.; Bergman, R. G. Chem. Sci. 2013, 4, 1023-1027. doi:10.1039/c2sc21519e

25. Newcombe, S.; Bobin, M.; Shrikhande, A.; Gallop, C.; Pace, Y.; Yong, H.; Gates, R.; Chaudhuri, S.; Roe, M.; Hoffmann, E.; Viseux, E. M. E. Org. Biomol. Chem. 2013, 11, 3255-3260. doi:10.1039/c3ob27460h

26. Boogaerts, I. I. F.; Nolan, S. P. J. Am. Chem. Soc. 2010, 132, 8858-8859. doi:10.1021/ja103429q

27. CCDC 949310 (2), 949311 (3), 949312 (7), 949313 (8), 949314 (10), 949315 (11) and 949316 (12) contain the supplementary crystallographic data for this paper. These data can be obtained free of charge from The Cambridge Crystallographic Data Centre (CCDC) via http://www.ccdc.cam.ac.uk/data_request/cif.

28. Vogler, A.; Kunkely, H. Coord. Chem. Rev. 2001, 219-221, 489-507. doi:10.1016/S0010-8545(01)00348-4

29. Ito, H.; Saito, T.; Oshima, N.; Kitamura, N.; Ishizaka, S.; Hinatsu, Y.; Wakeshima, M.; Kato, M.; Tsuge, K.; Sawamura, M. J. Am. Chem. Soc. 2008, 130, 10044-10045. doi:10.1021/ja8019356

30. Carlos Lima, J.; Rodriguez, L. Chem. Soc. Rev. 2011, 40, 5442-5456. doi:10.1039/c1cs15123a

31. Lu, W.; Kwok, W.-M.; Ma, C.; Chan, C. T.-L.; Zhu, M.-X.; Che, C.-M. J. Am. Chem. Soc. 2011, 133, 14120-14135. doi:10.1021/ja205831V

32. Cámara, J.; Crespo, O.; Gimeno, M. C.; Koshevoy, I. O.; Laguna, A.; Ospino, I.; Smirnova, E. S.; Tunik, S. P. Dalton Trans. 2012, 41, 13891-13898. doi:10.1039/C2DT31019H

33. Partyka, D. V.; Teets, T. S.; Zeller, M.; Updegraff, J. B.; Hunter, A. D.; Gray, T. G. Chem.-Eur. J. 2012, 18, 2100-2112. doi:10.1002/chem.201101891

34. Heckler, J. E.; Zeller, M.; Hunter, A. D.; Gray, T. G. Angew. Chem., Int. Ed. 2012, 51, 5924-5928. doi:10.1002/anie.201201744 
35. Gao, L.; Partyka, D. V.; Updegraff, J. B., III; Deligonul, N.; Gray, T. G. Eur. J. Inorg. Chem. 2009, 2711-2719. doi:10.1002/ejic.200900307

36. Hirtenlehner, C.; Krims, C.; Hölbling, J.; List, M.; Zabel, M.; Fleck, M.; Berger, R. J. F.; Schoefberger, W.; Monkowius, U. Dalton Trans. 2011, 40, 9899-9910. doi:10.1039/c1dt11175b

37. To, W.-P.; Tong, G. S.-M.; Lu, W.; Ma, C.; Liu, J.; Chow, A. L.-F.; Che, C.-M. Angew. Chem., Int. Ed. 2012, 51, 2654-2657. doi:10.1002/anie.201108080

38. Gimeno, M. C.; Laguna, A.; Visbal, R. Organometallics 2012, 31 , 7146-7157. doi:10.1021/om300571m

39. Visbal, R.; Ospino, I.; López-de-Luzuriaga, J. M.; Laguna, A.; Gimeno, M. C. J. Am. Chem. Soc. 2013, 135, 4712-4715. doi:10.1021/ja401523x

40. Fujimura, O.; Fukunaga, K.; Honma, T.; Machida, T. Substituted phenylethynyl gold-nitrogenated heterocyclic carbene complex. WO Patent 2007139001 A1, Dec 6, 2004; pp 42 ff.

41. Fujimura, O.; Fukunaga, K.; Honma, T.; Machida, T. Gold complex, method for production of the gold complex, and organic ultraviolet electroluminescent element using the gold complex. WO Patent 2008050733 A1, May 2, 2008; pp $16 \mathrm{ff}$.

42. Fujimura, O.; Fukunaga, K.; Honma, T.; Machida, T. Substituted phenylethynyl gold-nitrogen-containing heterocyclic carbene complex. Jpn Patent JP 2008179550 A, 2008; pp $41 \mathrm{ff}$.

43. Zhao, Y.; Truhlar, D. G. Acc. Chem. Res. 2008, 41, 157-167. doi:10.1021/ar700111a

44. Gaussian 03, Revision D.02; Gaussian Inc.: Wallingford, CT, 2004.

\section{License and Terms}

This is an Open Access article under the terms of the Creative Commons Attribution License (http://creativecommons.org/licenses/by/2.0), which permits unrestricted use, distribution, and reproduction in any medium, provided the original work is properly cited.

The license is subject to the Beilstein Journal of Organic Chemistry terms and conditions:

(http://www.beilstein-journals.org/bjoc)

The definitive version of this article is the electronic one which can be found at: doi: $10.3762 /$ bjoc. 9.260 